\title{
ANALISIS MEKANISME TERJADINYA TEKANAN-LUAP DAN PREDIKSI TEKANAN PORI PADA LAPANGAN BD, CEKUNGAN JAWA TIMUR
}

\author{
RYAN SURJAUDAJA ${ }^{1,2}$, AGUS M. RAMDHAN², INDRA GUNAWAN² \\ 1. Husky-CNOOC Madura Ltd. (HCML), Jenderal Sudirman Kav 52, Jakarta 12190, Email: \\ ryan.itb@gmail.com \\ 2. Program Studi Teknik Geologi, Fakultas Ilmu dan Teknologi Kebumian, Institut Teknologi Bandung \\ (ITB), Jl. Ganesha No.10, Bandung, Jawa Barat, Indonesia, 40132.
}

\begin{abstract}
Sari - Cekungan Jawa Timur merupakan salah satu cekungan sedimen yang sudah terbukti secara sistem petroleum dan sangat prospektif sebagai target eksplorasi hidrokarbon. Namun, cekungan ini memiliki risiko operasi dalam pengeboran akibat kehadiran tekanan-luap, seperti ditunjukkan oleh masalah lost dan kick pada pengeboran sumur eksplorasi di Lapangan BD. Masalah dan risiko pengeboran dapat dikurangi dengan melakukan studi tekanan-luap, dimulai dari menentukan mekanisme terjadinya tekanan-luap, yang berujung dengan prediksi tekanan pori dan puncak tekanan-luap.
\end{abstract}

Temperatur $80^{\circ} \mathrm{C}$ dapat dicapai di kisaran kedalaman $1500 \mathrm{~m}$ SSTVD. Namun, berdasarkan plot-silang Dutta-Katahara, tidak terdapat indikasi terjadinya diagenesis mineral lempung smektit menjadi ilit. Hal ini dikonfirmasi juga oleh data XRD di salah satu sumur, yang menunjukkan dominasi mineral lempung kaolinit sepanjang interval sumur. Berdasarkan data reflektansi vitrinit, tidak terjadi transformasi kerogen menjadi hidrokarbon. Sejarah pemendaman menunjukkan kecepatan sedimentasi yang cepat, yang dapat mencapai 1723 $\mathrm{m} / \mathrm{juta}$ tahun. Berdasarkan hal-hal tersebut, mekanisme terjadinya tekanan-luap yang utama di lapangan ini adalah mekanisme loading. Mekanisme tersebut berkaitan dengan kecepatan sedimentasi yang tinggi akibat inversi, yang menyebabkan berlimpahnya suplai sedimen, yang puncaknya terjadi di Kala Plio-Pleistosen.

Tekanan pori di lapangan ini dapat diestimasi menggunakan data sonik dengan Metode Eaton. Estimasi tersebut dibantu oleh data tekanan pengukuran langsung maupun tidak langsung dan data pengeboran lainnya. Berdasarkan data sumur, puncak tekanan-luap di lapangan ini ada di kisaran 1500-1600 m SSTVD. Puncak tekanan-luap terdapat pada Formasi Lidah.

Kata kunci: tekanan-luap, loading, Metode Eaton, sejarah pemendaman, Cekungan Jawa Timur.

\begin{abstract}
The East Java Basin is one of the sedimentary basins with proven petroleum system and very prospective as an exploration target. However, drilling in this basin is a risky operation because of the presence of overpressure, which is shown by kick and lost during exploration wells drilling in BD Field as an example. Drilling problems and drilling risks can be reduced by doing overpressure study, including overpressure generating mechanism, pore pressure prediction, and estimation top of overpressure.
\end{abstract}

The temperature in this field can reach $80^{\circ} \mathrm{C}$ at the depth around $1500 \mathrm{~m}$ SSTVD. However, the Dutta-Katahara crossplot does not indicate any diagenesis of smectite to illite. It is also confimed by XRD data in one of the well, which shown domination of kaolinitic clay mineral. Based on the vitrinite reflectance data, there is no transformation of kerogene to hydrocarbon in this field. The burial history plot shows rapid sedimentation with the rate of 1723 $\mathrm{m} /$ million years. Based on those criterias, the main overpressure generating mechanism is interpreted to be loading mechanism. High sedimentation rate is related to the peak inversion in Plio-Pleistocene time, providing abundant of sediment supply into the basin.

Pore pressure in this field can be estimated by using sonic data with Eaton's method. Both direct and indirect pressure measurements, combine with drilling data are used to support this estimation. Based on well data, top of overpressure in this field is located at the depth around 1500-1600 m SSTVD. The top of overpressure is located within Lidah Formation.

Key words: overpressure, loading, Eaton's Method, burial history, East Java Basin. 


\section{PENDAHULUAN}

Lapangan BD merupakan lapangan hidrokarbon terbukti, terletak di lepas pantai sebelah selatan Pulau Madura (Gambar 1A). Sumur-sumur eksplorasi sudah membuktikan sulitnya mengebor di lapangan ini akibat kehadiran tekanan-luap, seperti kehadiran kick dan lost. Pemahaman mengenai mekanisme penyebab tekanan-luap, penentuan puncak tekanan-luap, dan prediksi tekanan pori diharapkan dapat meminimalisasi masalah pengeboran di sumur pengembangan berikutnya ataupun sumur di sekitarnya.
Secara geologi regional, Lapangan BD terletak di Cekungan Jawa Timur, di batas tenggara dari Kraton Sunda, dan merupakan cekungan belakang busur berumur Tersier. Berdasarkan data gravitasi terbaru, Smyth dkk. (2005) memodifikasi zonasi fisiografi Van Bemmelen dan mengklasifikasikan lapangan ini ke dalam Zona Kendeng (Gambar 1B, C). Pembentukan zona fisiografi tersebut erat kaitannya dengan sejarah tektonik di cekungan tersebut. Zona Kendeng merupakan zona depresi, tempat akumulasi sedimen, akibat adanya inversi yang mencapai puncaknya pada Plio-Pleistosen.
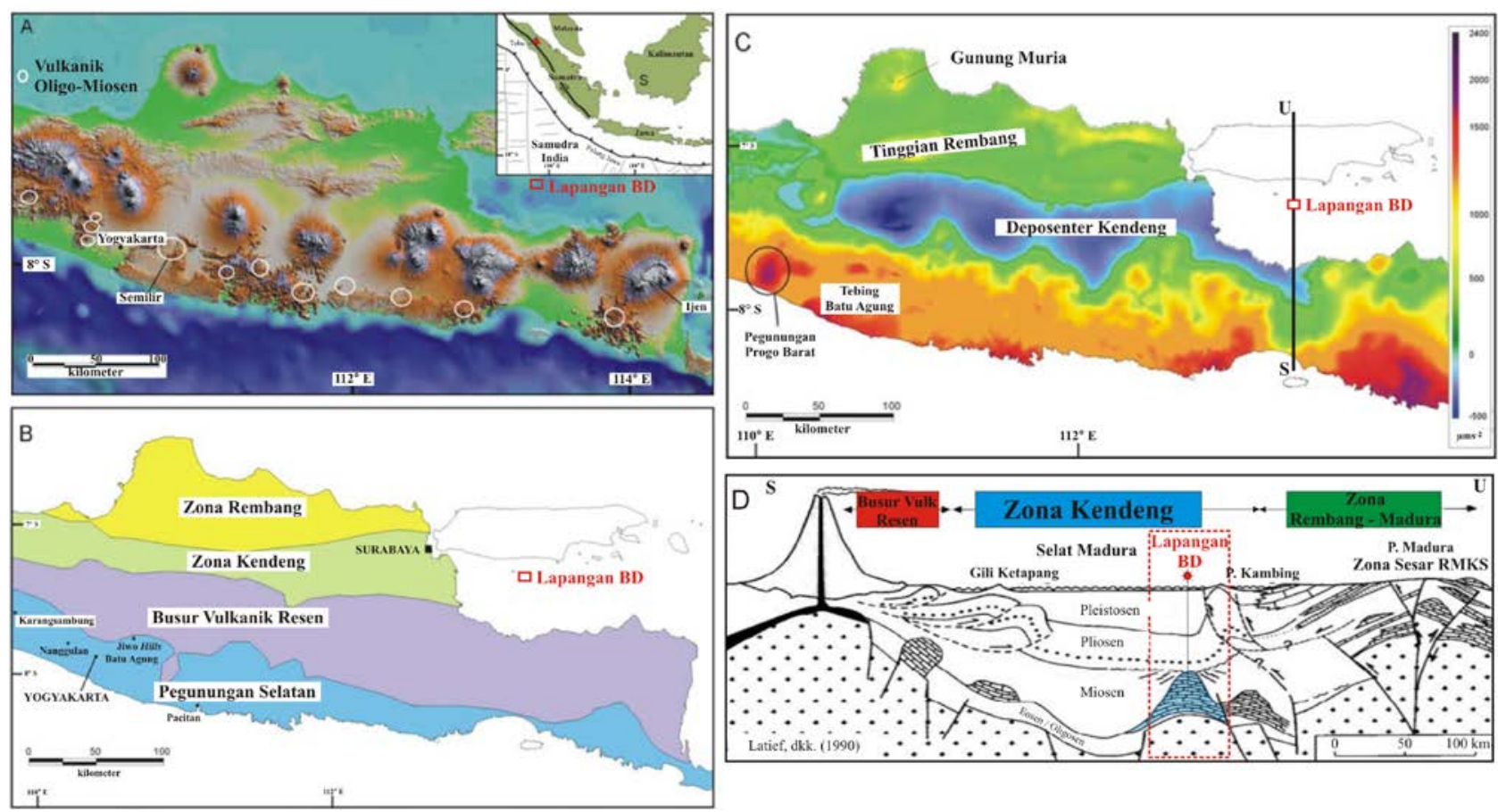

Gambar 1. Lokasi Lapangan BD berdasarkan (A) model ketinggian SRTM, (B) zonasi struktur dan sedimentasi modifikasi dari Van Bemmelen, (C) peta anomali Bouguer (Smyth dkk., 2005), dan (D) penampang utara-selatan (dimodifikasi dari Latief, dkk., 1990 dalam Satyana dkk., 2004).

\section{DATA DAN METODOLOGI}

\subsection{Data}

Data yang digunakan dalam penelitian ini meliputi (Gambar 2):

- 2 data sumur eksplorasi, yaitu B-1 dan
B-3 (data log, kecepatan interval, uji kandung lapisan, laporan pengeboran, hasil analisis laboratorium) dibor tahun 1987 dan 1989.

- 1 sumur pengembangan, yaitu B-3 (hanya data XRD) dibor tahun 2015. 


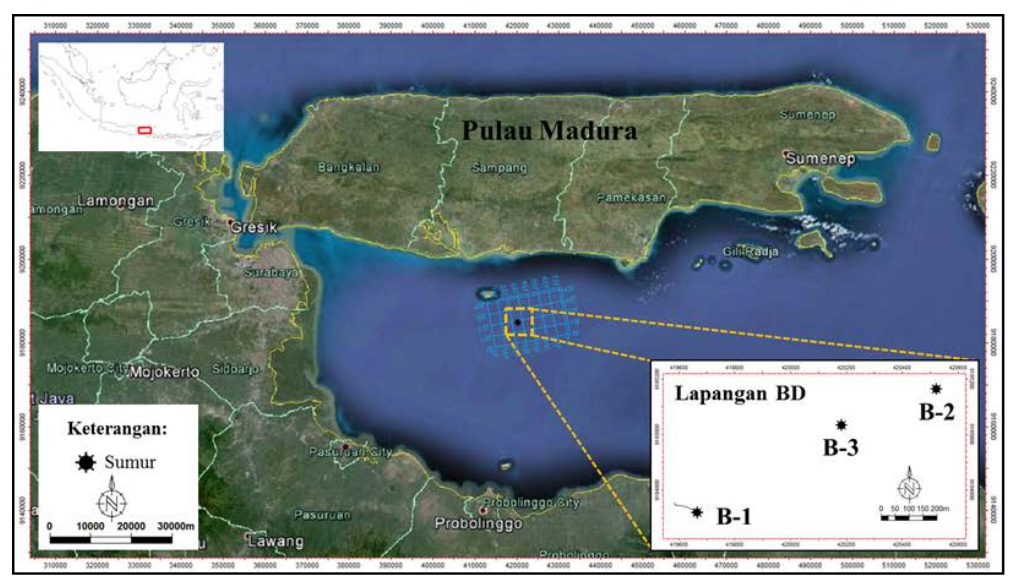

\begin{tabular}{|c|c|c|c|}
\hline \multirow{2}{*}{ Data } & \multicolumn{3}{|c|}{ Sumur } \\
\cline { 2 - 4 } & B-1 & B-2 & B-3 \\
\hline Log Lumpur & $\mathrm{v}$ & $\mathrm{v}$ & - \\
\hline $\begin{array}{c}\text { Log Tali } \\
\text { Kawat }\end{array}$ & $\mathrm{v}$ & $\mathrm{v}$ & - \\
\hline $\begin{array}{c}\text { Kec epatan } \\
\text { Interval }\end{array}$ & $\mathrm{v}$ & $\mathrm{v}$ & - \\
\hline $\begin{array}{c}\text { Uji Kandung } \\
\text { Lapisan }\end{array}$ & $\mathrm{v}$ & $\mathrm{v}$ & - \\
\hline $\begin{array}{c}\text { Laporan } \\
\text { (checkshot })\end{array}$ & $\mathrm{v}$ interval) & $(3$ interval $)$ & - \\
\hline Akhir Sumur & $\mathrm{v}$ & $\mathrm{v}$ & - \\
\hline Data Lab & Ro & Ro & XRD \\
\hline
\end{tabular}

Gambar 2. Data yang digunakan dalam penelitian.

\subsection{Metodologi}

Penelitian diawali dengan menentukan mekanisme penyebab tekanan-luap, diakhiri dengan prediksi tekanan pori dan puncak tekanan-luap (Gambar 3A). Secara garis besar, mekanisme penyebab tekanan-luap dapat dibagi menjadi 2, yaitu mekanisme ekspansi fluida dan loading. Umumnya tekanan-luap akibat ekspansi fluida akan berhubungan dengan kenaikan temperatur, seperti diagenesis mineral lempung smektit menjadi ilit yang terjadi di kisaran suhu $80^{\circ} \mathrm{C}$ (Boles dan Franks, 1979) atau transformasi kerogen menjadi hidrokarbon yang terjadi di kisaran suhu $70^{\circ}-120^{\circ} \mathrm{C}$ (Tissot dkk., 1987). Mekanisme loading umumnya terjadi akibat proses sedimentasi yang sangat cepat, lebih cepat daripada air keluar dari batuan, mengakibatkan batuan gagal kompak (disequilibrium compaction).

Penentuan mekanisme tekanan-luap, diawali dengan menghitung gradien temperatur di area penelitian. Jika temperatur lebih besar dari \pm $80^{\circ} \mathrm{C}$, kemungkinan tekanan-luap disebabkan oleh ekspansi fluida (diagenesis mineral lempung atau transformasi kerogen menjadi hidrokarbon). Diagenesis mineral lempung dapat dikonfirmasi dengan menggunakan plot-silang Dutta (2002) - Katahara (2006) (Gambar 3B) dan data XRD. Transformasi kerogen menjadi kerogen dapat dikonfirmasi dengan menggunakan data reflektansi vitrinit. Di lain sisi, jika temperatur lebih kecil dari \pm $80^{\circ} \mathrm{C}$, kemungkinan tekanan-luap disebabkan oleh loading. Hal ini dapat dikonfirmasi dengan sejarah pemendaman. Kecepatan sedimentasi $>100 \mathrm{~m} / \mathrm{juta}$ tahun dapat dikategorikan cepat (Swabrick dkk., 2002) dan berpotensi menyebabkan tekanan-luap. Pola dari data tekanan, log sonik/resistivitas, porositas, dan log densitas, dapat juga digunakan untuk menentukan mekanisme tekanan-luap (Gambar 3C, D).

Prediksi tekanan pori secara kuantitatif dapat dilakukan dengan menggunakan data log sumur, seperti data sonik, resistivitas, dan sebagainya. Log tersebut akan dijadikan dasar untuk membuat kurva normal compaction trend (NCT). NCT menggambarkan interval batuan sedimen yang mengalami kompaksi secara normal pada kedalaman yang dangkal yang kemudian diinterpolasikan pada interval yang lebih dalam. Penyimpangan pembacaan log dari NCT merupakan indikasi dari adanya tekanan abnormal (Gambar 4A).

Penentuan tekanan pori paling umum adalah menggunakan Metode Eaton. Eaton (1975) menghubungkan secara empiris hasil uji tekanan dengan log. Contoh log yang digunakan adalah log resistivitas, sonik, dan eksponen pengeboran (drilling exponent) di Teluk Meksiko (Gambar 4B).

Puncak tekanan-luap dapat didefinisikan sebagai titik kedalaman ketika tekanan sudah lebih besar dari tekanan hidrostatik. Penentuan puncak paling mudah jika terdapat data pengukuran tekanan, baik langsung ataupun tidak langsung, seperti RFT/MDT, uji kandung lapisan, dan berat lumpur. Indikator lain adalah keterdapatan connection gas atau background 
gas yang cenderung meningkat, kick, dan sebagainya. Penggunaan data log densitas, resistivitas, sonik, dan kecepatan interval di interval batulempung dapat digunakan untuk menentukan puncak tekanan-luap. Terkadang puncak tekanan-luap berasosisasi terhadap perubahan litologi dari yang didominasi oleh batupasir (batuan permeabel) ke batulempung (batuan impermeabel).
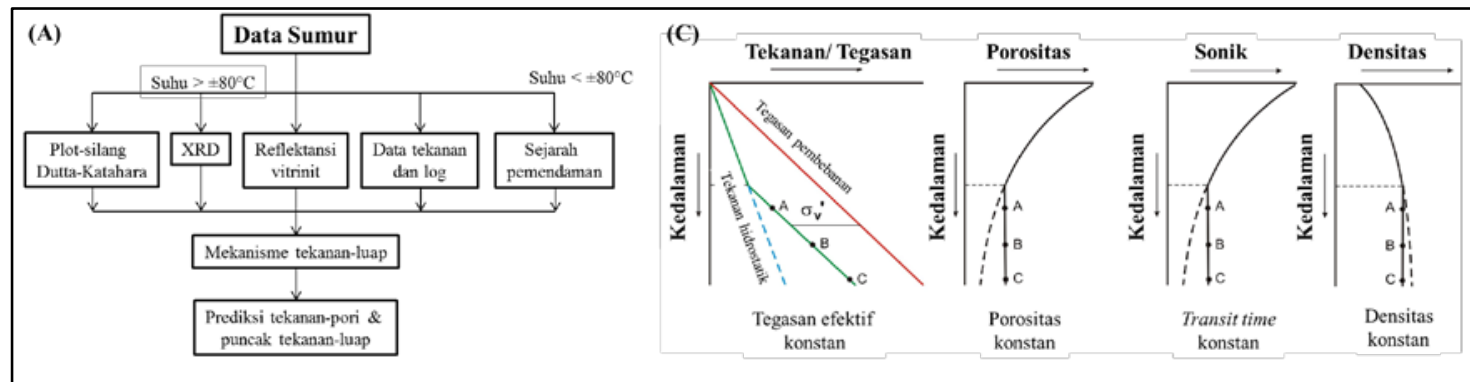

(B)

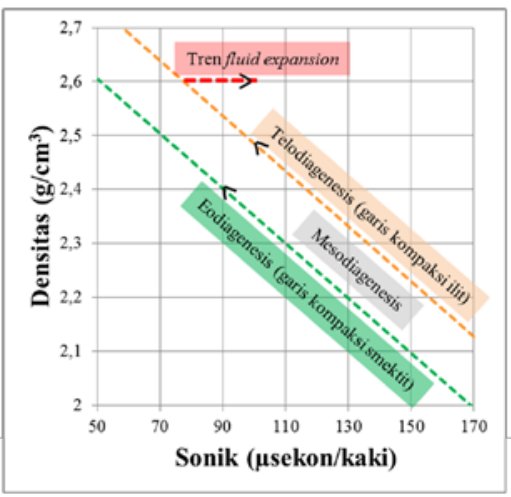

(D)

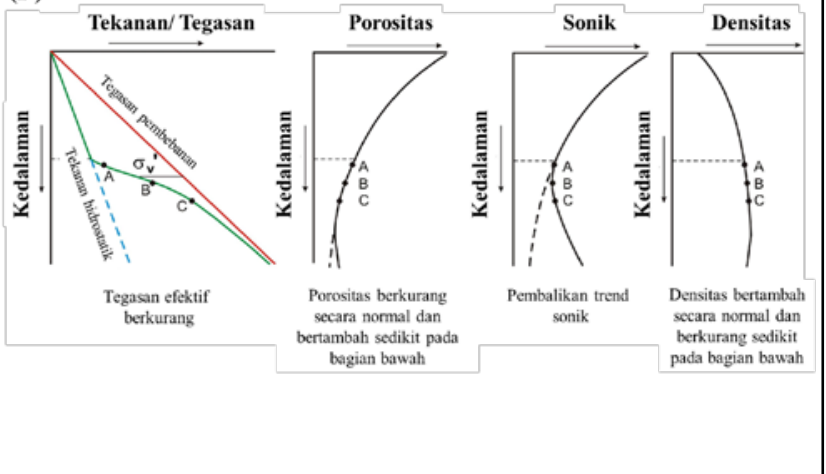

Gambar 3. (A) Data dan metodologi penelitian, (B) plot Dutta (2002) dan Katahara (2006), (C) karakteristik tekanan-luap akibat mekanisme loading (Ramdhan, 2010), dan (D) karakteristik tekanan-luap akibat mekanisme ekspansi fluida (Ramdhan, 2010).



Gambar 4. (A) Kurva NCT ideal, penyimpangan terhadap kurva tersebut menunjukkan keterdapatan tekanan-luap (Ramdhan, 2010), (B) rumus yang digunakan dalam Metode Eaton (Eaton, 1975). 


\section{HASIL}

Berdasarkan data tekanan langsung (uji kandung lapisan) maupun tidak langsung (berat lumpur) dari sumur B-1 dan B-2, jelas terlihat terdapat tekanan-luap di Formasi Kujung dan di lapisan yang lebih muda (Gambar 5A, B). Pola log dari kedua sumur tersebut menunjukkan adanya reversal sonik ataupun kecepatan interval. Namun, berdasarkan data tekanan dan pola log sulit ditentukan mekanisme penyebab tekanan-luap. Berdasarkan data temperatur di dasar sumur B-1 dan B-2, didapat gradien temperatur berkisar antara $3,2{ }^{\circ} \mathrm{C} / 100 \mathrm{~m}$ sampai $3,6^{\circ} \mathrm{C} / 100 \mathrm{~m}$. Temperatur $80^{\circ} \mathrm{C}$ dapat dicapai pada kisaran $1500 \mathrm{~m}$ SSTVD. Berdasarkan plot reflektansi vitrinit terhadap kedalaman SSTVD (meter) dari sumur B-1 dan B-2, dapat dilihat perubahan pola dari kategori tidak matang menjadi matang terjadi di kisaran kedalaman 2900-3050 m SSTVD (Gambar 5A, B).

Plot-silang sonik terhadap densitas pada sumur B-1 dan B-2 menunjukkan data masih dalam pola garis smektit dan ilit, tidak membentuk pola ekspansi fluida (Gambar 5A, B). Berdasarkan data XRD di sumur B-3, sepanjang interval sumur didominasi oleh mineral kaolinit (Gambar 5C). Jumlah mineral smektit sendiri berkurang setelah kedalaman $1500 \mathrm{~m}$ SSTVD dan bertransformasi menjadi mineral ilit, ditandai dengan penambahan jumlah ilit setelah kedalaman tersebut (Gambar 5C).



Gambar 5. (A) Plot tekanan dan log terhadap kedalaman, plot-silang Dutta-Katahara, plot-silang reflektansi vitrinit terhadap kedalaman dari sumur B-1, dan (B) sumur B-2, (C) plot data XRD dari sumur B-3. 
Berdasarkan kurva sejarah pemendaman, kecepatan sedimentasi mulai meningkat di Pliosen dan mencapai puncaknya di Pleistosen (Gambar 6). Kecepatan sedimentasi dapat mencapai $1723 \mathrm{~m} / \mathrm{juta}$ tahun dikategorikan sedimentasi cepat (Swabrick dkk., 2002).

Berdasarkan ringkasan analisis data-data sebelumnya penyebab utama tekanan-luap untuk interval batuan silisiklastik tersebut di Lapangan BD adalah mekanisme loading, akibat sedimentasi yang cepat terutama pada umur Plio-Pleistosen. Formasi Kujung terdiri dari batugamping terumbu ditutupi oleh batuan silisiklastik di sekitarnya. Batugamping sendiri tidak dapat menghasilkan tekanan-luap secara internal. Penyebab tekanan-luap di batugamping tersebut kemungkinan diakibatkan oleh adanya charging dari batuan silisiklastik di sekitarnya yang memiliki tekanan-luap.

Berdasarkan analisis sumur B-1 dan B-2, didapatkan puncak tekanan-luap terdapat di kisaran kedalaman 1500-1600 m SSTVD (Gambar 7A, B). Kedalaman puncak tekanan-luap kemungkinan berhubungan dengan dominasi batulempung, yang tidak mampu mengeluarkan air lebih cepat dibandingkan laju sedimentasi.

Estimasi tekanan pori menggunakan data sonik dengan Metode Eaton, pada interval batulempung. NCT dihitung pada interval batulempung, yang masih dalam tekanan hidrostatik normal pada masing-masing sumur B-1 dan B-2 (Gambar 7A, B).

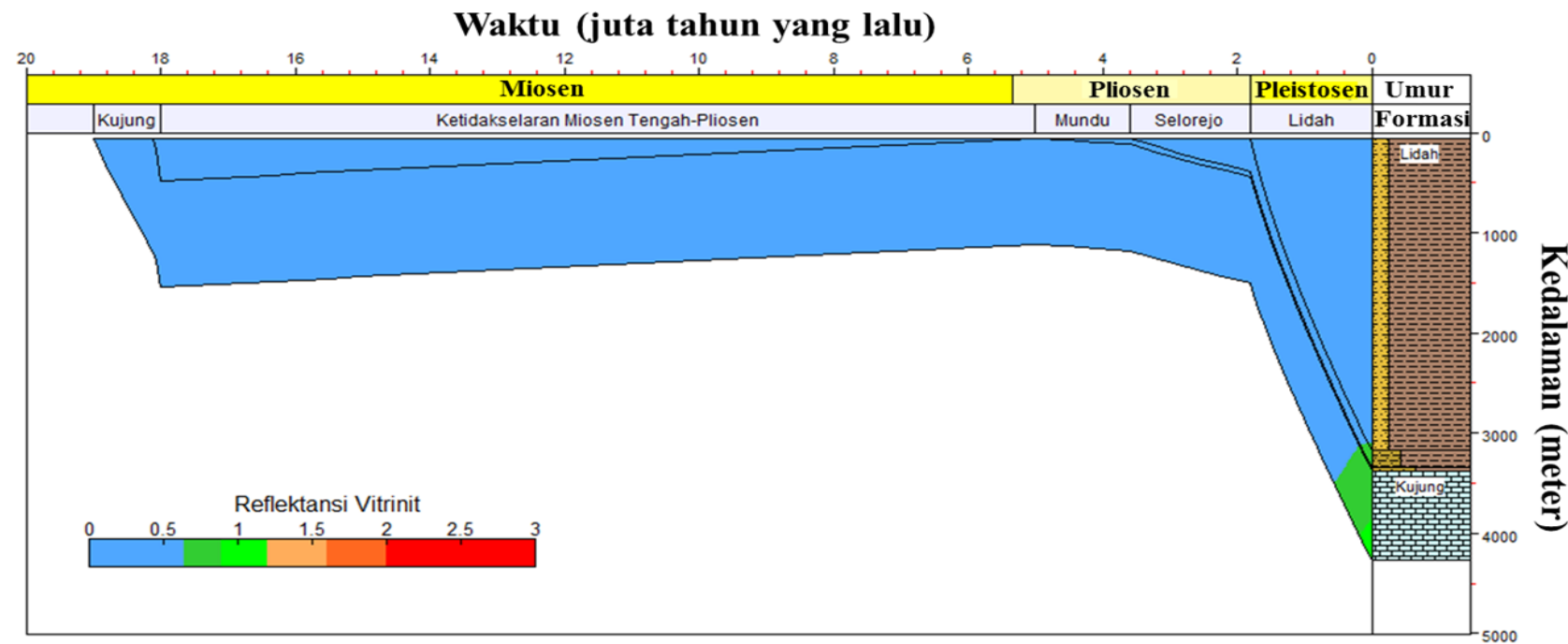

Gambar 6. Kurva sejarah pemendaman, menunjukkan kecepatan sedimentasi tinggi mencapai puncaknya di Pleistosen.


Gambar 7. (A) Estimasi tekanan pori dan puncak tekanan-luap menggunakan data sonik dan Metode Eaton di sumur B-1, dan (B) B-2. 
Berdasarkan pola estimasi tekanan pori pada sumur B-1 dan B-2, didukung oleh data tekanan dan data pengeboran, didapatkan pola tekanan pori seperti (Gambar 8). Dari permukaan sampai puncak tekanan-luap di kedalaman 1500-1600 m SSTVD, tekanan pori masih dalam keadaaan normal hidrostatik, dengan gradien 9,95 $\mathrm{MPa} / \mathrm{km}$. Dari puncak tekanan-luap sampai kedalaman 2150 m
SSTVD, tekanan pori akan naik secara drastis, dengan gradien bisa mencapai $37 \mathrm{MPa} / \mathrm{km}$. Dari kedalaman 2150 m SSTVD sampai puncak Formasi Kujung, gradien tekanan pori akan relatif paralel terhadap tegasan pembebanan, dengan gradien $19 \mathrm{MPa} / \mathrm{km}$. Tekanan pori akan berkurang sedikit di Formasi Kujung dan akan relatif paralel terhadap gradien hidrostatik 9,95 MPa/km.

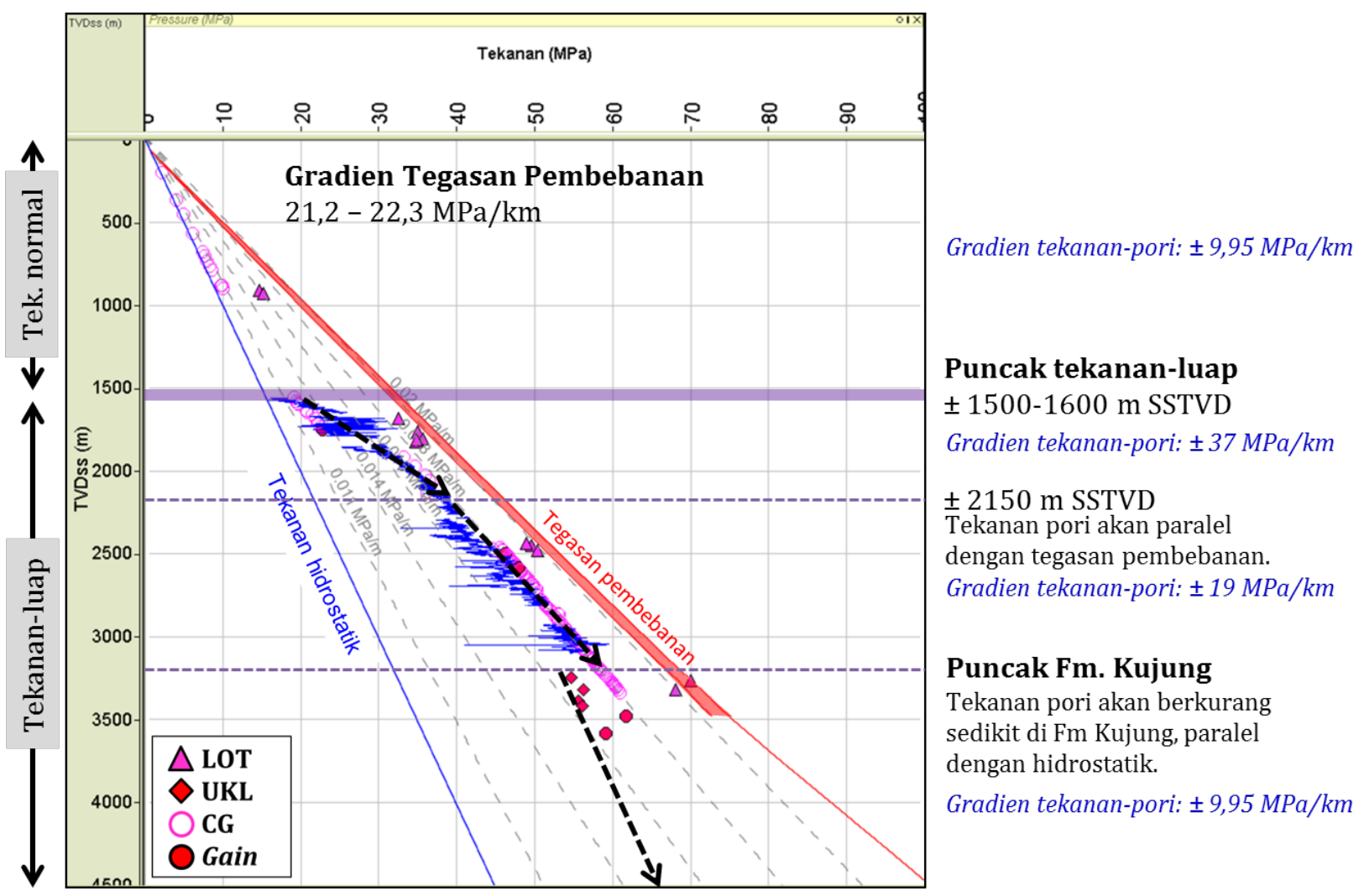

Gambar 8. Rangkuman estimasi tekanan pori di Lapangan BD.

\section{KESIMPULAN}

Tekanan-luap di Lapangan BD terdapat pada interval batugamping Formasi Kujung dan batuan silisiklastik yang lebih muda di atasnya. Masalah-masalah pengeboran di sumur eksplorasi B-1 dan B-2 pada Lapangan BD berkaitan dengan kehadiran tekanan-luap tersebut. Mekanisme utama penyebab tekanan-luap di Lapangan BD pada interval batuan silisiklastik yang lebih muda dari Formasi Kujung adalah loading, akibat laju sedimentasi yang tinggi. Tekanan-luap pada interval batugamping Formasi Kujung disebabkan oleh adanya charging dari batuan silisiklastik di sekitarnya yang memiliki tekanan-luap.
Puncak tekanan-luap di Lapangan BD ada di kisaran 1500-1600 m SSTVD. Tekanan pori dapat diestimasi menggunakan data sonik dengan Metode Eaton.

\section{UCAPAN TERIMA KASIH}

Penulis mengucapkan terima kasih kepada Husky-CNOOC Madura Ltd. (HCML) yang telah mengizinkan pemakaian data dalam penelitian ini. 


\section{DAFTAR PUSTAKA}

Boles, J. R. dan Franks, S. G. 1979. Clay diagenesis in Wilcox sandstone of Southwest Texas: implications of smectite diagenesis on sandstone cementation, Journal of Sedimentary Petrology, 49 no 1, 55-70.

Dutta, N. C. 2002. Deepwater geohazard prediction using prestack inversion of large offset $p$-wave data and rock model, The Leading Edge, February, 193-198.

Eaton, B. A. 1975. The equation for geopressure prediction from well logs, SPE 50th Annual Journal, SPE 5544.

Katahara, K. 2006. Overpressure and shale properties: stress unloading or smectite-illite transformation?, SEG 2006 Annual Meeting, SEG-2006-1520.

Ramdhan, A. M. 2010. Overpressure and compaction in the Lower Kutai Basin, Indonesia, Disertasi Program Doktor, Durham University, 29-73.

Satyana, A. H., Erwanto, E., dan Prasetyadi, C.
2004. Rembang - Madura - Kangean Sakala (RMKS) fault zone, East Java Basin: The origin and nature of a geologic border, Proceedings IAGI 2004.

Smyth, H., Hall, R., Hamilton, J., dan Kinny, P. 2005. East Java: Cenozoic basins, volcanoes, and ancient basement, Proceedings IPA 2005, IPA05-G-045.

Swabrick, R. E., Osborne, M. J., dan Yardley, G. S. 2002. Comparison of overpressure magnitude resulting from the main generating mechanisms, 1 12 dalam Huffman, A. R. dan Bowers, G. L., ed., Pressure regimes in sedimentary basins and their prediction AAPG Memoir 76, 233 hal., American Association of Petroleum Geologists, Tulsa, Amerika.

Tissot, B. P., Pelet, R., dan Ungerer, P. H. 1987. Thermal History of sedimentary basins, maturation indices, and kinetics of oil and gas generation, AAPG Bulletin, 71 no 12 , 1445-1456. 